\title{
FUNCIONES GANADERAS DE LOS ALBACARES, EN LAS FORTALEZAS MUSULMANAS
}

\author{
Por \\ MIKEL DE EPALZA
}

La toponimia árabe ha dejado muchos restos en la Península, hasta nuestros días (1). Esos nombres de lugar son auténticos documentos históricos, porque suelen describir con bastante exactitud lo que los árabes veían en esos parajes, desde el punto de vista de sus características físicas, del poblamiento humano o de otras relaciones geográficas entre el hombre y su entorno. Esos documentos son particularmente preciosos, junto a los arqueológicos (no sólo de monumentos, sino de estructuras productivas o residenciales más modestas), porque la documentación escrita suele ser escasísima o totalmente inexistente en la mayor parte de las zonas rurales, para el período árabe de la historia medieval, especialmente en Al-Andalus.

Pero al estudiar la historia de esos poblamientos a partir de la toponimia árabe, es fundamental conocer bien la lengua árabe y el significado de esos nombres de lugar cuando antes eran sencillos nombres comunes en árabe. La mayoría de los topónimos árabes son descriptivos. Esas descripciones corresponden a una peculiar visión árabe del entorno humano, adaptada a la lengua árabe. Por eso el análisis lingüístico de los términos árabes comunes, que dieron origen a unos topónimos concretos, es fundamental para poder estudiar aquellas estructuras sociales que había en AlAndalus y que dejaron esos topónimos.

(1) Es obra clásica y que hay que consultar siempre. M. ASIN PALACIOS, Contribución a la toponimia árabe de España, Madrid-Granada, 1944 (los topónimos alicantinos de esta abra los recogió V. Martínez Morellá en une pequeña publicación), a completar con los estudios lingüísticos de $F$. CORRIENTE, $A$ Grammatical Sketch of the Spanish Arabic Dialect Bundle, Madrid, 1977, y estudios particulares, como los de E. Terés. Para Sharq Al-Andalus, los recientes estudios de C. BARCELO TORRES, Toponimia aràbica del País Valencià. Alqueries $i$ castells, Valencia, 1983; M. J. RUBIERA: «Toponimia arábigo-valenciana: falsos antropónimos beréberesn, Homenaje Manuel Sanchis Guarner, Revista Valenciana de Filología; Villena en la calzada romana y árabe, Villena, Ayuntamiento; M. J. RUBIERA - M. DE EPALZA Los nombres árabes de Benidorm y su comarca. Estudio de toponimia histórica. Benidorm. Ayuntamiento (en prensa). Para los topónimos árabes de la región murciana, los estudios de A. Steiger, J. Bernal, C. Hernández Carrasco y R. Pocklington. Bibliografía casi exhaustiva en M. ARIZA, intento de bibliografia de la Onomástica hispánica, Cáceres, 1981. 
Por otra parte, los topónimos árabes sufren frecuentes modificaciones fonéticas al ser utilizados y transcritos por los agentes lingüísticos de los superestratos romancehablantes (castellano-aragoneses o catalanes de la conquista cristiana, sobre todo en el siglo XIII, para el País Valenciano), Ilegando a camuflarse en auténticos topónimos romances (2). En un trabajo paralelo a éste (3), se trata sobre todo de los equívocos producidos por nombres árabes de estructura semejante o que no tienen más que un solo grafema equivalente a diversos fonemas árabes, en romance.

Pero, yendo más allá de los problemas estrictamente lingüísticos, quisiéramos mostrar en los casos concretos que presentamos, cómo esos nombres árabes expresan sobre todo distribuciones del espacio rural o urbano, especialmente en el terreno agropecuario.

Se ha querido dar a esas denominaciones un sentido político o de relaciones jurisdiccionales. Creemos que no hay ninguna relación entre esos nombres y las estructuras políticas supuestamente implicadas. Menos aún pueden probar esos topónimos la existencia de esas estructuras, desconocidas por otras fuentes escritas y que no se dan en otras zonas del mundo sociopolítico árabe medieval. Hay que tener en cuenta además que la toponimia árabe no suele reflejar instituciones sociales o políticas. Aun las más importantes de éstas, que están perfectamente documentadas en las fuentes escritas árabes, no se encuentran en la toponimia, como por ejemplo las coras, los iqlims, las iqtaats, ni los hisn en el sentido de gobernorato, etc.

En el caso de los albacares -como en el de los rafales- nos parece que son denominaciones primordialmente agropecuarias, lo que no excluye alguna otra función secundaria o circunstancial, o la evolución ulterior de su función, en algún caso en particular. Son espacios para guardar el ganado, en las ciudades, en las fortalezas, en las huertas o en el campo en general. Se distinguen lingüística y territorialmente de otros espacios urbanos o rurales, que llevan evidentemente otros nombres.

No podemos extendernos aquí sobre la importancia de la ganadería en Al-Andalus, base de alimentación y de muchas industrias urbanas (lanas, cueros...). El almacenamiento del ganado en zonas urbanas y periurbanas planteaba unos problemas de convivencia con los hombres y con la agricultura intensiva de las huertas. De ahí los espacios acotados, con nombres particulares, que se les destina: albacares y rafales.

Es por tanto la finalidad principal de este trabajo el esclarecer esos términos y realidades y también el mostrar la endeblez de ciertas teorías

(2) Ver ejemplos en M. DE EPALZA, «Al topónimo Guardamar. Guardamar ("Río de las Dunas"), Valdemoro "Río Amargo") y Mesleón ("Posada de Fuentes"): tres topónimos árabes romanceados", Revistá del instituto de Estudios Alicantinos, Alicante, 29, 1980, 205-214, 38, 1983, 89-99; IDEM, «Mutxamel/Muchamiel (Alacant): origen àrab d'aquest topònims, But/letí de la Societat d'Onomàstica. Barcelona, XVI, 1984 . 15-17.

(3) M. J. RUBIERA, «Rahạles y rafals, reales y raals, arrabales y ravals», Sharq A/-Andalus, Estudios Arabes, Alicante, I, 1984, en este mismo volumen. 
expuestas recientemente a partir de esos topónimos árabes, especialmente en zona valenciana.

\section{El albacar en las fortalezas}

El bacar (arabismo generalmente lexicalizado con artículo en zona catalanohablante, albacar) es una parte amplia de una fortaleza, dentro del recinto amurallado, pero sin ninguna construcción de tipo militar o civil. Su etimologia árabe permite adivinar su función, que no es la que se ha ido diciendo hasta ahora y que resume incidentalmente Miquel Barceló: «bagar o recinte emmurat destinat a servir temporalment de refugi, com els que han estudiat P. Guichard i A. Bazzana a la part peninsular de L'Orient (sharq) d'Al-Andalus» (4). Entra esta definición dentro de un esquema general de estos autores franceses sobre la función administrativa (feudalismo musulmán) de las fortalezas, como "típics hisn (fortalesa) de refugi de les comunitats camperoles del seu entorn» (5).

Quisiéramos aportar precisiones sobre la función del al-baqqâr árabe y mostrar que las relaciones de la fortaleza con las comunidades rurales en nada se parecen al esquema social imaginado por Guichard y Bazzana, que es una transposición del feudalismo a la sociedad musulmana, aunque ellos se defiendan de hacerlo (6).

Para nuestras afirmaciones nos basamos también en dos estudios recientes, sobre la estructura urbana de Denia (7) y de Alicante (8). Ambas poblaciones son ciudades portuarias, cuya vigorosa vida ciudadana está atestiguada ampliamente durante gran parte de la historia medieval musulmana. El albacar de Alicante figura nominalmente en documentación moderna de la ciudad y el de Denia es deducción teórica del estudio de la estructura urbana de la ciudad en época musulmana. Lo mismo podría decirse de otras importantes ciudades musulmanas del interior del país, como Xàtiva (Játiva) (9) y Orihuela (10).

(4) M. BARCELO, "Oastîl al-"uyûn, una fortälesa desconeguda de Mayûrqa», L'Avenç, Barcelona, n. ${ }^{\circ}$ 65, noviembre, 1983, p. 11 (813). Guichard y Bazzana han expuesto sus teorías en numerosas publicaciones: $A$. BAZZANA, «Albacary: la fonction refuge dans le château hispano-musulman de la région valencianne", en Flaran 1: Château ot pouplements en Europe occidentale du Xe au XVII/e siècle, Auch, 1980, pp. 192-197; IDEM, «Premiers éléments d'une carte archéologique du Sharq Al-Andalus», Archéologie Médiévale, $X$, 1980, 324-325; IDEM, "La défense des communautés rurales dans l'Espagne musulmane», Perspectives aériennes. Les paysages et leur histoire, París, 1983, pp. 105-122; y sobre todo en el libro colectivo, BAZZANA, GUICHARD, POISSON y otros, Habitats fortifiés et arganisation de l'espace en Méditerranée Médié. vale, Lyon, 1983.

(5) M. BARCELO, o.c.

(6) Ver P. GUICHARD, "Le problème de rexistence de structures du type "féodalı dans la saciété d'Al-Andalus (l'exemple de la région valencienne) ), en Structures féodales et féodalisme dans l'Occident Méditerranéen (X-XIII siècles), Roma, 1980, pp. 699-725

(7) J. WARS PEREZ, La ciutat de Dénia. Evolució i permanència del fet urbà, Alacant, 1982.

(8) M. BEVIA, «Formació del País Valencià i canvi urbà: el cas d'Alacant), L'Espill, València, 15, tardor 1982, 53-82.

(9) A. VENTURA, «Topònims urbans de Xàtiva», But/letí de la Societat d'Onomàstica, Barcelona, Xili, 1983. $52-63$.

(10) R. AZUAR RUIZ, Castellologia medieval alicantina: Area Meridional, Alicante, 1981, pp. 141-157. 
La comparación de estos albacares valencianos con sus equivalentes del reino nazarí de Granada, en el siglo $X V$, es particularmente reveladora.

Quisiéramos mostrar que las estructuras de un poblado musulmán provienen de las ciudades, que son los modelos urbanísticos por excelencia, en la civilización musulmana. Las estructuras de los castillos rurales -estudiados prioritariamente por A. Bazzana y P. Guichard- no son generalmente originales, sino calcos de las ciudades. En otras ciudades árabes, como Valencia y los puertos del Mágreb, la función de los albacares no ha sido estudiada (con la excepción muy interesante de Ceuta (11)), por varias razones: el albacar es una construcción arquitectónica tan sencilla que no llama la atención de los arqueólogos; es una natural expansión de las ciudades, por lo que es un terreno invadido por ella, en época otomana o moderna, en Al-Andalus $y$ en el Mágreb; no tuvo probablemente nombre propio en esa época en el Mágreb o se ha perdido su recuerdo; etc.

\section{Significado de la palabra albacar}

Baqqâr (quizás baqârr, aunque no está atestiguado este último nombre como tal en los principales diccionarios árabes) significa propiamente "guarda de ganado bovino». El término bagar, de la misma raíz árabe, aparece en el capítulo $2 .^{\circ}$ del Corán (sûrat al-baqara, «Azora de la Vaca»). El que se trate de bóvidos -raros en la Arabia pétrea, pero abundantes en las llanuras irrigadas en las que se extenderá la lengua árabe-islámica- o de otros animales con cuernos en general parece desprenderse del léxico especial del árabe dialectal de Al-Andalus (12). La forma nominal al-bacar, tal y como se conserva en romance hispánico, más bien recuerda el nombre de oficio de la misma raíz, baqqâr, "ganadero» o "que cuida del ganado», nombre que se aplica también a la constelación estelar del Boyero. En este sentido puede afirmarse que los albacares de las fortalezas árabes tienen el sentido primordial de guardar el ganado. A eso corresponden su amplia extensión, dentro del recinto amurallado, $y$ el que no se halle en él, del punto de vista arquitectónico, ningún resto de construcción.

Este sentido agropecuario viene refrendado por la autoridad lingüística e historiográfica de Dozy, que zanja en las discusiones de su tiempo sobre el origen de la palabra albacara, en el castellano del siglo XV. Su texto merece ser citado en su totalidad (13). De la Crónica de Don Juan // se deduce

(11) C. GOZALBES CRAVIOTO, «El "albacar" en las fortificaciones de Ceuta», Jábegà, Málaga, 29, 1980, 61-65.

(12) Ver R. DOZY, Supplément aux dictionnaires arabes, reimpresión en Beirut, 1968, t. I, p. 102.

(13) "Au XVe siècle albacara avait encore un tout autre sens, celui de tour dans les fortificacions selon Nuñez, et M. de Gayangos, dans une note sur la Chronique du connétable Don Miguel Lucas (dans le Memor. hist esp., VIII, 308), cite ce passage de la Crónica de Don Juan // (édit. de Logroño, 1517, fol. 9 d), où il est question de la ville de Setenili «é tiene una puerta al cabo de la villa, y en el comienzo del castillo, con una albacara, cerca de una torre muy grande é muy hermosa; é tras esta albacara tiene otra como manera de alcázar, é hay dos puertas desta albacara al alcázarn, et plus loin (ibidd): "y embióles tres lombardas para que tirassen en derecho del albacara del alcázar cel castillo, co estava la puerta». M de Gayangos ne doute pas de l'origine arabe de ce mot, qui selon lui désigne une espèce de tour, et il en propose deux étymologies; mais l'une est aussi inadmissible que l'autre; il n'est pas nécessaire de les réfuter, car il va de so que al-bakara, poulie, convient aussi peu que al-wakra let non pas a/-waqara comme écrit M. de Gayan- 
claramente que la albacara tenía una función de avituallamiento de la fortaleza en vacas y terneras.

Muy bien ha estudiado esta función Carlos Gozalbes Cravioto en su artículo sobre el albacar de Ceuta (14). Allí la estructura y la función del albacar quedan confirmadas por la vecindad de este topónimo con otros topónimos árabes relacionados también con el ganado: el barrio de AFQassâbûn, "los carniceros», y la fonda Ganim, «oveja», colectivo que significativamente puede decir también "ganado fruto de botín» (15).

Otra ciudad árabe aporta una nueva confirmación sobre el origen $y$ función de los albacares. Es la Málaga del siglo XV, donde el espacio que llamamos albacar se llama en castellano «corral de la alcazaba» (16).

Hay que tener en cuenta que Málaga sigue musulmana hasta finales del siglo XV, una época en la que el castellano es mucho más fuerte lingüísticamente que en tiempos del arcaismo albacara castellano de la Crónica de Don Juan // o del catalán del siglo XIII, que aceptan el arabismo sin traducirlo. En Málaga se traduce y se le da el significado que tiene bacar en árabe, "corral de la alcazaba».

También queda claro el significado agropecuario de la palabra árabe albacar por una visita personal al lugar del topónimo rural de Albacar, en el término municipal alicantino de Benimarfull (17). Se trata de una pequeña balsa («balsa Albacar», nos dijeron en el pueblo), metida en el fondo de un vallecillo, a media altura de un cauce seco. La balsa se alimentaba de una captación de agua en túnel, de la ladera izquierda, de sistema de qanât, estudiado por M. Barceló (18). El origen árabe de la denominación se deduce

gos). nid d'oiseau. Il est étrange que ce savant ne se soit pas aperçu que le passage de la chronique du connétable qu'il commentait, fournit à la fo is l'étymologie et la véritable signification du mot. ll y est question de l'approvisionnement d'une forteresse et on y lit: «metióles dentro en el alvacara (var. albacara) fasta quatrocientas vacas, y terneras las más famosas $y$ gordas que jamás se vieron». L'albacara contenait done quatre cents vaches et veaux; or, al-bakar est en arabe le mot ordinaire pour boeufs, et il est clair qun 'albacara signifiait, non pas une espèce de tour, mais une vaste étable où les habitants et la garnison d'une forteresse mettaient le gros bétail. Les Arabes disaient sans doute «l'étable des bacar», mais les Espagnols disaient albacara tout court. Que si l'on relit à présent le passage de la Chronique de Don Juan II, on verra qu'il ne contient rien qui s'oppose à cette interprétation, et les deux endroits que j'ai cité sont les seuls, si je ne me trompe, où ce terme se trouves (R. P. A. DOZY \& W. H. ENGELMANN, Glossaire des mots espagnols et portugais dérivés de l'arabe, 1869 (reimpresión, Amsterdam, 1982), pp. 60-61).

(14) Ver nota (11).

(15) Julián de Zulueta, alcalde de Ronda (prov. de Málaga) y gran conocedor de su serranía, me informa de un albacar con una torre aislada rodeada de muros bajos, que parecen para guardar ganados, en una altura (el Cerro del Aguila, cota 519 metros) que domina la llanura de Arcos y Jerez (la frontera islamo-cristiana del siglo $X I V$ y $X V$ ) y que podría haber servido para guardar el fruto de las razias musulmanas por la lianura cristiana. Es una hipótesis coherente con lo que estudiamos aquí.

(16) F. GUILLEN ROBLES, Málaga musufmana, Málaga, 1880 (reimpresión, Málaga, 1981, pp. 470-471), con un mapa reproducido y estudiado por C. GOZALVEZ CRAVIOTO, "Las corachas hispano-musulmanas», Jábega. Málaga, 34, 1981, 61-70. Idéntica estructura en la Albacara de Ronda: zona periurbana con cercado bajo y sin valor defensivo, con ausencia de construcciones en su interior (L. TORRES BALBAS, Obra dispersa, vol. 2, Madrid, 1981, pág. 376, reproducción de Al-Andalus, (X, 1944, pág, 463). El estar en parte baja de una ciudad de altura y muy bien fortificada excluye aquí cualquier finalidad defensiva y explica bien la función meramente ganadera del albacar.

(17) Ver J. L. ROMAN DEL CERRO - M. DE EPALZA, Toponimia mayor y menor de la provincia de Alicante. Listado por municipios, Alicante, 1983, pág. 85.

(18) M. BARCELO, «Qanât(s) a Al-Andạlưs, Documents d'Anàlisi Geográfica, Bellaterra (Barcelona), 2, 1983, 3-22. 
con bastante seguridad de lo apartado del paraje, del sistema de captación de agua y de construcción de la balsa y de la estructura lingüística de la propia palabra, con artículo árabe, a/-bacar. Se trata de una balsa para beber el ganado. En el País Valenciano hay otros topónimos semejantes, algunos muy deformados, pero no es éste el objeto de este estudio.

\section{Función del albacar en la fortaleza}

De todo eso se deduce que la función del albacar en las fortalezas musulmanas es fundamentalmente alimenticia y ganadera: es el sitio donde los habitantes del castillo-fortaleza-población guardan sus reses. Es una ampliación del corral de una casa o habitación campesina, a nivel de la ciudad musulmana. Es su "reserva de carne», su "despensa», lo que en las ciudades modernas corresponde al «frigorífico del matadero municipal».

En efecto, la conservación del ganado, en una ciudad musulmana, supone un recinto defendido y un pequeño pastizal, para la conservación temporal de las reses, hasta su consumo. El ambiente natural de crianza de ese ganado ha sido el campo, en pastoreo más o menos semi-nómada o en los corrales o rafales de las zonas peri-urbanas de la ciudad. La ciudad o la fortaleza han adquirido ese ganado -por intercambio comercial, por apropiación militar, por concepto de pago fiscal, o por todo ello a la vez- y necesita simplemente un lugar para guardarlo, para su paulatina desaparición, según las necesidades de la guarnición militar y de la población civil. Esto supone, evidentemente, la particular estructura alimenticia musulmana, de rica elaboración cárnica (19).

Una prescripción especial de la religión musulmana puede explicar también la particular necesidad de tener un lugar para conservar las reses, especialmente las vacas, que son el baqar por antonomasia, en árabe. En efecto, la religión musulmana piohibe matar a los animales preñados o que den leche. El texto de un jurista con cargo municipal en Málaga en el siglo XIII atestigua que esa prescripción se exigía y que supondría lógicamente unas instalaciones urbanas para conservar a esos animales mientras dieran leche $y$ estuvieran en estado (20).

Esta función general y constante en el conjunto de las necesidades de la ciudad-fortaleza musulmana parece mucho más probable -tiene más pruebas- que la de «refugio temporal de los campesinos de los alrededores», como postulan Guichard y Bazzana. Esta utilización eventual del lugar alto, como por ejemplo en el caso de Burriana sitiada por los cristianos, en manera alguna explicaría la constante presencia del albacar en las estruc-

(19) Ver actuales estudios de M. Marín, M. Espada Burgos y míos personales. En Cataluña, ver el inicio esperanzador de J. GARCIA I FORTUNY - P. BALANYA I ABADIA, "Notes sobre l'ús i el consum del safrà", Arrets de Catalunya, Barcelona, 1, 1984, págs. 51-54.

(20) Ver traducción del texto árabe: «El enviado de Dios... prohibió... degollar las hembras que tienen leche.... «/el jefe de la policía municipal/ prohibirá que degüellen un animal sarnoso... ni las hembras preñadas, $\mathrm{n}$ las que tienen leche...» (P. CHALMETA GENDRON, «EI "Kitâb fî âdâb al-hisba" (Libro del buen gobierno del zocol de AI-Saqatî), Al-Andalus, Madrid-Granada, XXXI1/2, 1967, pág. 366, y XXXIII/1, 1968, 166-167). 
turas urbanas musulmanas y el alto coste de la construcción y conservación de sus murallas. El refugio es una eventualidad, la conservación del ganado es una constante.

Que no tiene función defensiva lo confirma también lo endeble de la construcción de su recinto. Azuar advierte en Orihuela que parte del recinto no tiene más de $90 \mathrm{cms}$. de altura (21) y Beviá ha recogido una curiosa documentación sobre Alicante (22) en la que los cristianos se quejan de lo endeble del recinto del albacar. Es evidente que lo empleaban para una finalidad defensiva que no habia tenido en época árabe.

\section{Las relaciones fortaleza-población rural}

Se ha querido ver en las fortalezas rurales un sistema de defensa para los pueblos o alquerías (23). El albacar sería el lugar de refugio de la población rural, defendida por el castillo, en eventuales momentos de peligro.

Esta estructura no explicaría la función del albacar en las fortalezas urbanas, desde el momento en que está demostrada su existencia en ciudades que poseen su propia muralla y sistema defensivo, como Ceuta, Málaga, Alicante, Denia, Xàtiva (Játiva), etc.

Pero aun limitándonos al ámbito rural, eso supondría unas relaciones y unos lazos muy fuertes entre los castillos y los habitantes de sus alrededores, que en manera alguna corresponden al modo de gobierno musulmán.

El sistema musulmán de soberanía se puede definir, en primer lugar, de una forma negativa. No se basa en unas relaciones de señor a territorio y sus habitantes, como en el sistema feudal rural europeo, sino en una relación de autoridad con los grupos humanos, que se expresa por la sumisión tributaria. Estos tributos, que la autoridad sita en la ciudad de la que dependen las fortalezas recoge periódicamente por o con la fuerza, es -en ámbito rural- una actuación depredatoria sobre los productos del campo. Este sistema puede apreciarse en un conjunto documental muy rico, del reino nazari de Granada, en el que el elemento ganadero tiene mucha importancia (24).

Pero, por el abundante poblamiento de las ciudades musulmanas -centros del poder político superior- y la variable climatología agrícola mediterránea, los productos tienen que conservarse durante todo el año y no pueden depender de la pura depredación permanente de un grupo mi-

(21) R. AZUAR RUIZ, aOrihuela, Castillo/El Castelln, Catálogo de monumentos y conjuntos do la Comunidad Valenciana, Valencia, t. I, 1983, págs. 666-667.

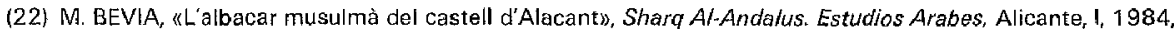
en este mismo volumen. A la objeción de que un muro de $90 \mathrm{cms}$. de altura no basta para encerrar a los animales me proporciona una respuesta D. Juan Giner, Cronista de Xaló (Jalón), con la técnica aún vigente en el agro valenciano de poner encima del muro una red de espinos.

(23) Ver bibliografía de notas (4) y (6).

(24) Ver A. GONZALEZ PALENCIA, «Documentos árabes del Cenete (siglos XII-XV)n, Al-Andalus, Madrid. Granada, V, 1940, 301-382; «Ádición a los documentos árabes del Cenete», ibíd, VI. 1941, 477-480. 
núsculo señorial, como en el feudalismo europeo. De ahí la preferencia constante por los productos agropecuarios conservables y de fácil transporte: ganado, aceite, mosto o pasas, etc. (25).

Por eso la ciudad árabe tiene unas estructuras coherentes, para la subsistencia alimenticia que depende del campo: conserva en la ciudad y sus alrededores los principales productos (productos agrícolas no perecederos, en sus zocos o alhóndigas; legumbres frescas, en las huertas periurbanas; ganado, en el albacar de la fortaleza o en los rafales/rafals periurbanos). Los albacares de las fortalezas rurales tendrían una función semejante, aunque en el estado actual de nuestros conocimientos, sólo se puede emitir la hipótesis más probable de que eran unos simples depósitos de ganado.

Esto explica la constante e importancia del albacar en el urbanismo musulmán. Pero es también una manifestación de las relaciones entre las fortalezas y las comunidades agropecuarias que les rodean: no están aquéllas para defender a éstas, sino para depredarlas tributariamente con relación a las ciudades, centro fundamental de la sociedad musulmana medieval, especialmente en el Sharq Al-Andalus (Levante de la Península) (26).

El albacar, de profundo arraigo en la arquitectura militar de Al-Andalus, según la documentación recogida por $E$. Terés (27), pudo tener otras funciones secundarias o cambiar en época cristiana, pero creemos que su función fundamental fue la que su nombre árabe indica: quarda de ganado.

(25) En el Sharq Al-Andalus, se nota ya este sistema en las condiciones del pacto de Teodomiro con los primeros conquistadores musulmanes.

(26) Sobre la urbanización y arabización de esta región, ver M. DE EPALZA, «Los beréberes y la arabización del País Valenciano», Homenaje Manuel Sanchis Guarner, Revista Valenciana de Filología (en prensa).

(27) En zona cordobesa y documentado en el siglo XI, ver el estudio de los «albacar» y "albacara» («amplios recintos murados al pie de una fortalezá, donde se encerraba el ganado») de E. TERES, (Al-'Aqaba. Notas de toponimia áraben. Al-Andalus, Madrid-Granada, XLIII, 1978, 370-371. 